\title{
A compreensão de textos de problemas matemáticos: aspetos metalinguísticos e metacognitivos
}

\section{The comprehension of the texts of mathematical problems: metalinguistic and metacognitive aspects}

\author{
Ana Paula Couceiro Figueira*, Maria Antonietta Pinto** \\ *FPCE.UC, **Universidade de La Sapienza
}

\begin{abstract}
Resumo
Apresentamos uma série de exercícios destinados a desenvolver habilidades ou capacidades metalinguísticas aplicadas a textos ou problemas matemáticos. São uma série de problemas de matemática normalmente utilizados no final do $1^{\circ}$ ciclo, podendo ser utilizados, mesmo, em outros ciclos de ensino. Os exercícios compartilham importantes pontos comuns em objetivos e modalidades: 1) sensibilizar professores e alunos para a forma como conceitos e perguntas são formuladas, 2) os alunos praticam uma série de habilidades metalinguísticas, nomeadamente, metasemânticas, metagramáticas e metapragmáticas, 3) os exercícios são sugeridos para serem praticados enquanto atividades de sala de aula, sob a orientação de professores.

Palavras-chave: capacidades metalinguísticas; compreensão de textos; resolução de problemas matemática.
\end{abstract}

\begin{abstract}
We present a series of exercises designed to develop metallinguistic skills or abilities applied to texts or mathematical problems. They are a series of mathematical problems usually used at the end of the first cycle, and can be used even in other cycles of education. The exercises share important common points in terms of objectives and modalities: 1) to sensitize teachers and students to the way concepts and questions are formulated; 2) students practice a series of metallinguistic skills, namely metasemantic, metagrammatic and metapragmatic, 3) exercises are suggested to be practiced as classroom activities under the guidance of teachers.

Keywords: Metalinguistic capabilities; Text comprehension; Mathematical problem solving.
\end{abstract}

O nível de consciência metalinguística depende do desenvolvimento intelectual global e é determinado, até certo ponto, pelo contexto sociocultural. As crianças 1 expostas a ambientes familiares e escolares ricos linguisticamente, e em que existem livros e pessoas com hábitos de leitura, desenvolvem melhor e mais

\footnotetext{
${ }^{1}$ Termos como crianças, professor, ensino, etc. e eles são usados como uma designação genérica não marcado em gênero, para que cobrem ambos os homens e mulheres.
}

rapidamente as suas habilidades linguísticas e metalinguísticas. Estas capacidades melhoram a utilização da linguagem, tornando conscientes certos componentes e funcionamentos que, a partir desse momento, podem ser manipulados para melhorar a expressão e compreensão oral e escrita (Pinto \& El Euch, 2015). Além disso, há evidências sobre a relação entre o nível de desenvolvimento da consciência metalinguística e o nível de desempenho em diferentes temas e tarefas escolares (leitura, matemática, escrita, etc.), pelo que a promoção dessa consciência deva ser uma tarefa a implementar na escola, com rigor, consistência, regularidade e de forma sistemática.

No caso concreto de compreensão de textos escritos, há que ter em conta que é graças às habilidades metalinguísticas, e especialmente aos processos mobilizados pela leitura e pela escrita, se realiza a transição de uma modalidade de pensamento ligada ao contexto a uma outra mais madura, desligada dele, mais abstrata e imprescindível, para desenvolver destrezas complexas de interpretação de textos de todos os tipos e âmbitos (escolar, social, profissional, etc.) e progressivamente mais elaborados e extensos. Este facto, já destacado no trabalho pioneiro de Tunmer, Pratt e Herriman (1984), revela a importância do elemento metacognitivo e metalinguístico na compreensão leitora e, portanto, a necessidade de incorporar nas salas de aula, de todas as etapas e áreas, atividades que, de forma específica, auxiliam os alunos a processar os textos próprios de cada uma, para que possam interpretá-los de forma profunda e ajustada aos objetivos previstos ou estipulados de leitura.

Compreender um texto não consiste somente em detetar as ideias que contem e em estabelecer a coerência entre elas, dado que as unidades discursivas têm um significado global que vai mais além do que a soma das ideias que o integram. Durante o processo de leitura, estas são submetidas a procedimentos de depuração, abstração e elaboração em virtude dos quais se atribui ao texto uma coerência global.

A exigência de recorrer a estruturas cognitivas de alto nível para explicar os processos de compreensão deriva 
do importante componente inferencial destes; de facto, as operações principais que se aplicam para compreender o material escrito são três (Núñez, 2015):

a. Prever, antecipar ou formular hipóteses sobre o que pode acontecer a seguir, sobre como será o texto ou como pode terminar. Requer um leitor ativo que coloca em funcionamento os seus conhecimentos linguísticos, culturais, etc. e as suas experiências de leitura.

b. Inferir consiste em compreender aspetos que não estão explícitos no texto, aplicando ou atualizando dois recursos principais:

1. O conhecimento que possuímos sobre o mundo e sobre o contexto (inferências pragmáticas).

2. O raciocínio formal (inferências lógicas). Inferências são operações fundamentais de compreensão que permitem dar sentido a diferentes palavras, unir proposições e completar as partes de informação ausentes ou implícitas no texto. São as que permitem estabelecer a coerência local, entre frases próximas ou entre o que se acabou de ler e o que se está a ler, e a global, conexão entre partes distantes do texto ou entre este e o conhecimento prévio do leitor, dos textos (Escudero, 2010).

c. Controlar é uma atividade metacognitiva através da qual se monitoriza o funcionamento do processo cognitivo para poder solucionar as dificuldades encontradas ou os erros cometidos. Este último componente, a autorregulação do processo, é essencial para garantir a compreensão leitora, pois é ele que permite controlar como funciona e resolver as dificuldades encontradas no seu transcurso para poder avançar na elaboração do sentido do texto. Calero (2011) define-o em três palavras: consciência, controlo e regulação e, consequentemente, podem estabelecer-se quatro processos associados à metacognição:

1. Saber que objetivos se deseja alcançar (planificação);

2. Selecionar a melhor estratégia para atingir esses objetivos (execução);

3. Controlar, durante o processo de "construção" do conhecimento, se são adequadas as estratégias (controlo ou supervisão);

4. Avaliar os resultados obtidos e verificar a execução ou não dos objetivos previamente estabelecidos (avaliação).

A metacompreensão não implica somente o conhecimento consciente declarativo, ou seja, a mera tomada de consciência e expressão do que se sabe e de como se sabe, mas também uma dimensão procedimental ou de atuação que se aplica na gestão de situações de aprendizagem. Esta última interessa substantivamente do ponto de vista educativo dado que tornar as pessoas mais conscientes do seu desempenho cognitivo repercute-se numa melhoria substancial deste e, como consequência, na eficácia das aprendizagens de todo o tipo. Daqui decorre a necessidade da educação escolar possibilitar atividades com esta finalidade para que o aluno automatize as estratégias, com base em exercícios e experiências de vão da prática guiada pelo professor ou educador à prática autónoma. Neste sentido, é de realçar ainda, por um lado, que o conhecimento metacognitivo surge em idade precoce e que evolui até à idade adulta, desenvolvendo-se especialmente na adolescência, ou seja, durante a escolarização. E, por outro lado, que a utilização dos recursos cognitivos próprios não é espontânea. Havendo necessidade de ser aprendida de forma que, quando há necessidade de enfrentar tarefas ou problemas concretos, possa ser ativada automaticamente, selecionando-se a estratégia mais pertinente a cada situação.

\section{Os exercícios}

Apresentamos uma série de exercícios destinados a desenvolver habilidades ou capacidades metalinguísticas aplicadas a diferentes tipos de textos, especificamente, textos ou problemas matemáticos. Eles abordam os dois níveis de idade dos testes metalinguísticos envolvidos no Projeto MATEL (Ensaios de Sensibilização Metalinguística em Línguas Europeias 543277-LLP-1-2013-1-IT-KA2-KA2MP), ou seja, o MAT-2 (sigla em inglês para Metalinguistic Ability Test n-2, 9-14 anos), e MAT-3 (sigla em inglês para Metalinguistic Ability Test n-3, 16 anos e mais), ou os THAM.2 e THAM.3, na versão do Português Europeu (Figueira \& Pinto, 2017, in press).

Os principais objetivos pedagógicos destas atividades são:

1) consciencializar os alunos para o poder da linguagem como veículo de conceitos e intenções comunicativas e como guia para a interpretação de códigos não-verbais (sistemas numéricos, algébricos, icónicos, de notação musical, etc.). Ao longo das atividades sugeridas neste documento, o/a professoro/a leva os seus alunos a perceber que o veículo linguístico dos conceitos é tão importante quanto os próprios conceitos;

2) melhorar o controlo cognitivo num instrumento tão poderoso (isto é, a linguagem), treinando as habilidades específicas necessárias para a sua análise, nomeadamente as habilidades metalinguísticas.

As atividades de formação são apresentadas a partir da pergunta geral "Quais são os elementos-chave a detetar no texto?". Seguem-se perguntas mais precisas para identificar os pontos específicos a interpretar, parafrasear ou ligar a outros elementos e o processo de realização das operações certas de execução. Por último, mas não menos importante, os alunos são convidados a recapitular, destacando os aspetos que mais os surpreenderam, as palavras que foram "iluminantes" para eles (as "palavras amigáveis") e as que foram confusas (as "palavras inimigas"). As atividades de treino são apresentadas como um jogo para descobrir "palavras amigas", "palavras inimigas" e a forma de transformar as "inimigas" em "amigas".

\section{Os problemas}

Todos os problemas ou situações/tarefas a resolver seguem,

1. A sequência das atividades metalinguísticas e metacognitivas

Para cada problema, apresenta-se:

- O texto;

- A análise das características estruturais do texto, tanto do ponto de vista das operações matemáticas como 
do ponto de vista dos elementos chave para o compreender. Este material tem por objetivo identificar as dificuldades específicas que cada problema coloca e a base sobre a qual o professor colocará as suas perguntas aos alunos;

- As atividades a realizar na aula, sobre a forma de perguntas, nas quais se inclui uma questão geral e questões específicas.

A questão principal tem por objetivo orientar os alunos através de um primeiro rastreio dos elementos "que é preciso observar". Naturalmente, e conforme as aulas, a participação dos alunos pode ser mais ou menos ativa e equilibrada no grupo, mas é importante que o professor dê um primeiro sinal, orientando a 'olhar' para o que é preciso utilizar, sobre o material, antes de empreender todo o cálculo.

Com base nas primeiras respostas, o professor colocará perguntas mais específicas e pontuais que poderão incitá-los a interpretar este ou aquele ponto, a parafrasear ou melhor explicar como se pode fazer para compreender e realizar a operação matemática a efetuar. Trata-se de aspetos puramente metalinguísticos e metacognitivos.

Ou seja, os alunos serão convidados a recapitular os aspetos que mais os surpreenderam, as palavras que lhes pareceram 'amigas' e aquelas que lhes pareceram 'inimigas', isto é, aquelas que, respetivamente, foram determinantes para compreenderem o passo a realizar, e aquelas que, ao contrário, as confundiram. No primeiro problema, esta recapitulação é tratada em grupo e de maneira detalhada, enquanto nos problemas seguintes, é deixada aos alunos para um trabalho individual.

A escolha dos problemas propostos neste documento é feita privilegiando os textos, tendo em conta um léxico muito simples e genérico. Os problemas de geometria são descartados pois possuem sempre uma terminologia e noções especializadas. Da mesma forma, os problemas de álgebra não são considerados pois são expressos, essencialmente, sob um sistema de notação algébrica.

A série de problemas propostos aqui não é certamente exaustiva. Não visa senão sensibilizar o professor para a prática de um método de reflexão que poderá construir com os seus alunos. Durante e no fim do processo, os alunos perceberão a relevância da utilização do método de reflexão, para além dos problemas específicos. O professor poderá, eventualmente, criar outras atividades metalinguísticas sobre outros problemas à sua escolha.

\section{Problema: um exemplo}

\section{Texto}

"por ocasião de uma festa de aniversário, para fazer convites, um grupo de crianças organiza-se da seguinte maneira:

- A Margarida decidiu utilizar cartões vermelhos, amarelos e verdes e fazer 90 convites por cor.

Quantos convites terá de fazer no total?

- O Guilherme faz 24 convites por dia.

Quantos terá feito numa semana?

- O Marco organiza os seus convites em 12 grupos de 15.

Quantos convites preparou?

- A Ana, pelo contrário, fez 24 de 8 cada.
Quantos realizou?

- Quem fez mais convites, entre Marco e Ana?"

\section{Características estruturais}

Operações aritméticas

- Multiplicações simples.

Elementos linguísticos chave:

- Múltiplas pesquisas de equivalência de sentido;

- Quantificadores distributivos;

- "por" como sinónimo de "por cada" (por cor, por dia);

- "de" como sinónimo de "cada é de..." (grupo de 15, 24, de 8);

- $\quad$ Pronomes relativos de valor anafórico: (fez, vai preparar) que treinam a procura de um antecedente;

- Equivalência numérica da série "vermelho, amarelo, verde" e do número 3 , quantidade não explicitada;

- Equivalência numérica da palavra "semana" e da expressão "sete dias", quantidade não explicitada;

- Sinónimo dos verbos "realizar", "preparar" e "fazer".

\section{Na sala de aula}

Como atualizar as competências na sala de aula,

"por ocasião de uma festa de aniversário, para fazer convites, um grupo de crianças organiza-se da seguinte forma:

1. A Margarida decidiu utilizar cartões vermelhos, amarelos e verdes e fazer 90 convites por cor. Quantos convites terá realizado no total?"

a) Pergunta geral

a. $\quad \mathrm{O}$ que é preciso observar para compreender o que é preciso fazer?

b) Questões específicas

a. Como poderemos dizer de outra maneira "fazer 90 convites por cor"?

b. Como compreendemos que a Margarida utiliza todos os seus cartões?

c. Como fazemos para escolher a melhor operação em relação ao que nos é pedido?

2. "O Guilherme preparou 24 cartões por dia. Quantos terá feito numa semana?"

a) Questão geral

a. O que é preciso observar para compreender o que é preciso fazer?

b) Questões específicas

a. Como poderemos dizer de outra forma "fazer 24 cartões por dia"?

b. Como poderemos dizer de outra forma "quantos numa semana"?

c. Como fazemos para escolher a melhor operação em relação ao que nos é pedido?

3. "O Marco organiza os seus convites em 12 grupos de 15. Quantos convites terá preparado?"
a) Questão geral
a. $\quad \mathrm{O}$ que é preciso observar para compreender o que é preciso fazer?

b) Questões específicas 
a. Como poderemos dizer de outra forma "em 12 grupos de $15 \%$ ?

b. Como fazemos para escolher a melhor operação em relação ao que nos é pedido?

4. "Ana, pelo contrário, fez 24 de 8 cada. Quantos fez?"

a) Questão geral

a. O que é preciso observar para compreender o que é preciso fazer?

b) Questões específicas

a. Que quer dizer "fez"?

b. Como poderemos dizer de outra forma "fez 24 de 8 cada"?

c. Como fazemos para escolher a melhor operação em relação ao que nos é pedido?

5. "Quem fez o maior número de convites, entre Marco e Ana?"

a) Questão geral

a. O que é preciso observar para compreender o que é preciso fazer?

b) Questão específica

a. Como poderemos dizer de outra forma "entre Marco e Ana", nesta frase?

\section{Recapitulando}

Devem ter notado que, muitas vezes, as palavras “inimigas" são pequenas e aparentemente muito simples. Por outro lado, para uma mesma operação aritmética por exemplo, a multiplicação, no caso do problema acima - existem várias maneiras de a exprimir verbalmente.

"por cor"

"por dia"

"de 8"

Outros exemplos de "pequenas palavras" enganadoras, traiçoeiras, "inimigas":

“em" ("fez") pede uma interpretação: "em” de quê?

"entre" ("entre Marco e Ana") pede uma ligação entre os resultados obtidos pelos indivíduos e não entre os indivíduos diretamente.

Repararam também que, por vezes, as palavras podem ser facilmente transformadas em números? Nestes casos, são palavras "amigas". Por exemplo, "semana" equivale a 7. Em outros casos, certas palavras são simplesmente sinónimos e não têm nenhuma influência sobre os números e as operações a efetuar. No problema acima, os verbos "preparar", "realizar" e "fazer" podem ser utilizados uns no lugar dos outros sem mudar o sentido geral das frases.

\section{Referências}

Arpinati, A. M. \& Musiani, M. R. (2004) Matematica in azione. Aritmetica volume A. Bologna: Editore Zanichelli.

Calero, A. (2011). Cómo mejorar la comprensión lectora. Estrategias para lograr lectores competentes. Vizcaya:Wolters!Kluwer.

Escudero, I. (2010). Las inferencias en la comprensión lectora: una ventana hacia los procesos cognitivos en segundas lenguas. Revista Nebrija de Lingüística Aplicada,7(4),1`32.

Girotti, G. (2010). Compiti di magia. Milano: Mondadori Education.

Jessner, U., Hofer, B. \& Pinto, M.A. (2015). MKT-2. Metalinguistischer Kompetenztest Teil 2. Innsbruck, Studia Universitätsverlag Innsbruck.

Núñez Delgado, P., \& Pinto, M. A. (2015). THAM-2. Test de Habilidades Metalingüísticas (9- 14 años). www.matelproject.com.

Núñez Delgado, P., \& Pinto, M. A. (2015). THAM-2. Test de Habilidades Metalingüísticas (9- 14 años). www.matelproject.com.

Núñez, P. (2006). Taller de comprensión lectora. Barcelona: Octaedro.

Núñez, P. (2015). La comprensión lectora. Aspectos teóricos y didácticos. In J. Mata, P. Núñez, \& J. Rienda (eds.). Didáctica de la lengua y la literatura. Madrid: Pir.mide.

Pinto M. A. \& El Euch, S. (2015). La conscience métalinguistique. Théorie, développement et instruments de mesure. Québec: Presses de l'Université Laval.

Pinto M. A., Candilera, G., \& Iliceto, P. (2003). TAM-2. Test di abilita metalinguistiche n.2 (9-14 anni). La valutazione dello sviluppo metalinguistico tra scuola elementare e scuola media. Roma: Scione Editore.

Pinto, M. A. \& El Euch, S. (2015). La conscience métalinguistique. Théorie, développement et Instruments de mesure. Québec: Presses de l'Université Laval.

Pinto, M. A. \& Fulgenzi, D. (2014). QUASI UN BIG BANG ! Potenziare le abilità di riflessione sulla lingua. Valore italiano: Lilamé.

Pinto, M. A. (2015). Metalinguistic Excercises as Classroom Activities. Roma, Sapienza Università Editrice.

Pinto, M. A., Candilera, G., \& Iliceto, P. (2003). TAM-2. Test di abilita metalinguistiche n.2 (9-14 anni). La valutazione dello sviluppo metalinguistico tra scuola elementare e scuola media. Roma: Scione Editore.

Soldaini, G. (2010). Tutto esercizi DOC. matematica 5. Firenze: Giunti Scuola.

Tunmer, W. E., Pratt, C., \& Herriman, M. L. (1984). Metalinguistic Awareness in Children. Theory, Research and Implications. Berlin: Springer.

Vacca, R., Artuso, B., \& Bezzi, C. (2011). Aritmetica 1. Bergamo: Edizioni Atlas.

Vacca, R., Artuso, B., \& Bezzi, C. (2014). Algebra. Modelli del pensiero matematico. Bergamo: Edizioni Atlas. 